\title{
Research Paper: The Effects of Active Memory Exercises on Intelligence Profile in Students With Specific Learning Disorder
}

\author{
Sabora Tahmasbnezhad ${ }^{1}$, Narges Firoozzadeh Pasha ${ }^{2}$, Morteza Homayounnia Firoozjah ${ }^{3^{*}}$, Alireza Homayouni
}

1. Department of Counselling, Faculty of Humanities, Allameh Tabatabai University, Tehran, Iran.

2. Department of Psychology, Faculty of Humanities, Sari Branch, Islamic Azad University, Sari, Iran.

3. Department of Physical Education, Faculty of Humanities, Farhangian University, Tehran, Iran.

4. Department of Psychology, Faculty of Humanities, Bandargaz Branch, Islamic Azad University, Bandargaz, Iran.

\begin{tabular}{|c|c|}
\hline $\begin{array}{l}\text { Use evour device to scan } \\
\text { and read the article online }\end{array}$ & dration: Tahmasbnezhad, S., Firoozzadeh Pasha, N., Homayounnia Firoozjah, M., \& Homayouni, A. R. (2021). The Effects \\
\hline 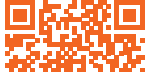 & $\begin{array}{l}\text { of Active Memory Exercises on Intelligence Profile in Students With Specific Learning Disorder. Journal of Practice in Clinical } \\
\text { Psychology, 9(2), 93-102. https://doi.org/10.32598/jpcp.9.2.703.1 }\end{array}$ \\
\hline 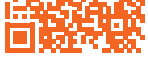 & dol'https://doi.org/10.32598/jpcp.9.2.703.1 \\
\hline
\end{tabular}

(c) (i) (8)

Article info:

Received: 23 Nov 2020

Accepted: 13 Feb 2020

Available Online: 01 Apr 202

\section{Keywords:}

Children, Intelligence,

Learning Disorders,

Intelligence, Wechsler scale

\section{ABSTRACT}

Objective: Active memory is the search engine of the mind. Active memory is a cognitive function responsible for preserving instant information, its manipulation, and its use in thinking. This study aimed at investigating the effects of active memory practices on intelligence profiles in students with Specific Learning Disorder (SLD).

Methods: This was a quasi-experimental study with a pretest-posttest and a control group design. The population of the study included elementary students of the East Bandpey region in Babol City, Iran, in 2019. The study participants were randomly divided into the experimental (21) and control (20) groups. The experimental group performed sixteen 45-minute active memory program sessions for 8 weeks, twice a week. Multivariate Analysis of Variance (MANOVA) was employed for data analysis.

Results: Research findings suggested that educational interventions on the verbal comprehension, perceptual reasoning, active memory, and overall scale have led to a significant difference between the experimental and control groups $(\mathrm{P}=0.280)$; however, there was no significant difference concerning the processing speed scale between the study groups $(\mathrm{P}=0.280)$.

Conclusion: The present study data suggested that educational interventions were the most influential factor on active memory and overall scale. Furthermore, applying active memory exercise, as a non-pharmacological approach, is recommended to improve the intelligence profile in children with SLD.

\section{"Corresponding Author:}

Morteza Homayounnia Firoozjah, PhD.

Address: Department of Physical Education, Faculty of Humanities, Farhangian University, Tehran, Iran.

Tel: +98 (911) 6257221

E-mail: mortzahomayoun@gmail.com 


\section{Highlights}

- Active memory is a cognitive function responsible for preserving instant information.

- The research focused improve the intelligence profile in children with SLD.

- The study data suggested that educational interventions were the most influential factor on active memory and overall scale.

\section{Plain Language Summary}

Active memory is the search engine of the mind. Active memory is a cognitive function responsible for preserving instant information, its manipulation, and its use in thinking. This study aimed to investige the effects of active memory practices on intelligence profiles in students with Specific Learning Disorder (SLD).

\section{Introduction}

pecific Learning Disorder (SLD) is a neurodevelopmental condition with a biological origin, and the basis of cognitive disorders (Gabriely, Tarrasch, Velicki \& Ovadia-Blechman, 2020). SLD is recognized by the following symptoms: reading words inaccurately or with difficulty; problems in meaning comprehension; dictation problems; difficulty in writing; difficulty in calculating numbers, and problems in math comprehension. Furthermore, these deficiencies interfere with educational activities, career performance, or individuals' daily living activities. Additionally, these problems begin during school years. It should not interfere with intellectual disability, visual, or hearing impairment, or other mental or neurological disorders; there must be a lack of teaching language skills and mental health issues (American Psychiatric Association, 2013).

Students with SLD present lower ability in all 4 hemispheres, compared to their Typically-Developing (TD) counterparts (Bang \& Nadig, 2020). A consequence of brain inefficiency is that individuals with SLD do acquire and process information; however, compared with TD children, they differ in its implementation and manifest some relevant issues. This problem is not accounted as a learning disorder; however, different patterns of executive dysfunction are observed in almost all subjects with SLD (Margolis et al., 2020). In students with SLD, evidence of deficiencies in executive functions and active memory in transferring and adaptation of working memory can be observed; such deficiency is manifested in math problems, time expression and approximate calculation, dyslexia, verbal short-term memory, and process- ing speed (Hammill \& Allen, 2020). Additionally, active memory is among the learning pattern manifestation in students. Active memory is the ability to preserve information in the mind during the performance of complex tasks. Active memory is among the significant cognitive processes which establish the major foundation of thinking and learning. This memory plays a sensitive role in children's learning. According to prior research, students with SLD present significantly lower performance in the verbal functioning of active memory, compared to their TD peers. They obtain lower scores in self-reporting strategies, selecting main ideas, understanding, and selecting appropriate strategies; all of which are positively related to verbal active memory (Knoop-van Campen, Segers \& Verhoeven, 2020).

Investigating some older theories suggests that students with SLD may experience some deficiencies in perceptual-motor development stages (O'Keefe \& Ward, 2020). Moreover, inefficiencies in the brain's cognitive management system affect multiple processing procedures of the brain and neurological systems, such as planning, organization, concentration, and attention, remembering details, as well as time and space management; various patterns of defects in executive performances are observed in almost all subjects with SLD (Casado-Aranda, Sánchez-Fernández \& Ibáñez-Zapata, 2020).

One approach to reinforce the intelligence profile in students with SLD is applying active memory exercises. Individuals with SLD may have less active memory experiences during their development. Active memory plays a critical role in children's learning during school years, and even in adulthood. Children with a limited active memory capacity encounter some problems in learning activities at school; ultimately, such deficits lead to 
learning disabilities and often inadequate performance in them. Thus, deficiencies in the active memory could lead to poor calculation, reading, and writing skills (Sweller, 2020). Scholars argued that after exercise intervention, the experimental group obtained higher scores in working memory tests; however, after posttest, no changes were observed in the working memory scores of the controls (Homayoun Nia Firoozjah \& Namdar Tajari, 2019). In a study (Maehler \& Schuchardt, 2011), children with SLD in the active memory tasks performed poorer than their DT counterparts. Moreover, extensive research explored the effects of applying learning strategies in teaching students with SLD (Groves, Kofler, Wells, Day \& Chan, 2020).

The relevant data demonstrated that teaching how to use learning strategies made significant differences in this respect. These strategies facilitate the acquisition of knowledge and skills and the organization of individuals' knowledge. Additionally, previous studies signified a significant relationship between active memory and intelligence profile (Kashani-Vahid, Kazemi Taskooh \& Moradi, 2019). Neural imaging studies (Shen et al., 2020) reported that working memory rehabilitation significantly affects the neural activities of working memory-related brain regions and improves their performance.

Scholars stated that all training groups performed significantly better on the transfer task than the controls; however, the training groups did not significantly differ from each other (Palmqvist, 2020). The implications of the findings concerning cognitive interventions and future Working Memory (WM) training studies are discussed. These results seriously question the practical and theoretical significance of active memory programs as methods of teaching active memory skills.

As mentioned above, investigations addressed the effects of active memory on improving challenges faced by children with SLD; however, these children may have intelligence weakness. Thus, the effects of implementing active memory-specific exercises should be addressed respecting deficiencies in cognitive and behavioral performance. Active memory plays a critical role in children's learning during school years and even in adulthood. Thus, the present study aimed to examine the effects of active memory exercise on intelligence profiles in children with SLD. A combination of these conditions remains undiscovered; thus, it is expected that by conducting this research, the capability of active memory exercises in the intelligence profile of individuals with SLD is addressed.

\section{Methods}

This was a quasi-experimental study with a pretestposttest and a control group design. The population of the study included primary school male students of Babol City, Iran. Given the weaknesses observed in their educational performance, the study subjects were referred to treatment centers for SLD by their teachers. The following instrument was applied in this study to collect the required data.

\section{Revised Wechsler Intelligence Scale for Children (WISC)}

The WISC was re-considered (revised) in 1972. This scale measures the intelligence of children aged 6 to 16 years, 11 months, and 30 days. This scale has 12 subtests. Children's verbal scale includes general information, comprehension, calculations, similarities, lexicons, and number memory sub-tests. The practical scale consists of image completion, image regulation, cubic design, parts insertion, encryption (the equivalent of an adult numeric code), and maze sub-tests. The WISC is an analytical test, i.e., scored based on the success level of the subject. The scoring method is not an all-or-nothing rule, but a degree of success. This test is specifically designed for children aged 5-15 years. The validity of its revised form was obtained based on the internal consistency of the overall scale (96\%), verbal scale (94\%), and non-verbal scale (90\%); based on retest validity, the same value was as follows: overall scale $(95 \%)$, verbal scale (93\%), and non-verbal scale (90\%). This test-retest method was employed with a one-month interval. It demonstrated to have greater reliability over two years. The standard error of measurement was proved to be 3.19 for the overall scale, 3.60 for the verbal scale, and 4.66 for the non-verbal scale (Wechsler, 2008). The revised WISC was considered as a working memory test in this study (St Clair-Thompson \& Gathercole, 2006). Sadeghi et al. (2011) reported the validity (79\%) and reliability $(81 \%)$ of this tool in Iranian students (Sadeghi, Rabiee \& Abedi, 2011).

Based on clinical evaluations, children with SLD had moderate intelligence and their academic achievement was below the healthy intelligence level. They had no other sensory impairments, such as visual, hearing, or motor defects; nor did they suffer from other conditions, such as Intellectual Disability (ID), autism, and so on.

Using the purposive sampling method, 41 students were selected as research subjects, and assigned to the experimental (20) and control (21) groups. The ex- 
Table 1. Dehn's training program to train active memory

\begin{tabular}{|c|c|c|}
\hline Sessions & Programs & Explanations \\
\hline 1 & Test your recall & $\begin{array}{c}\text { Make a list (grocery items, things to do, or anything else that comes to mind) and memorize it. An } \\
\text { hour or so later, see how many items you can recall. Make the list as challenging as possible for } \\
\text { the greatest mental stimulation. }\end{array}$ \\
\hline 2 & Let the music play & $\begin{array}{l}\text { Learn to play a musical instrument or join a choir. Studies suggested that learning something new } \\
\text { and complex over a longer time is ideal for the aging mind. }\end{array}$ \\
\hline 3 & $\begin{array}{l}\text { Do math in your } \\
\text { head }\end{array}$ & $\begin{array}{l}\text { Figure out problems without the aid of a pencil, paper, or computer. You can make this more dif- } \\
\text { ficult -and athletic- by simultaneously walking. }\end{array}$ \\
\hline 4 & Take a cooking class & $\begin{array}{l}\text { Learn how to cook a new cuisine. Cooking uses several senses (smell, touch, sight, \& taste) which } \\
\text { involve various brain parts. }\end{array}$ \\
\hline 5 & $\begin{array}{l}\text { Learn a foreign } \\
\text { language }\end{array}$ & $\begin{array}{l}\text { The listening- and hearing-involved tasks stimulate the brain. Furthermore, a rich vocabulary was } \\
\text { linked to a reduced risk for cognitive decline, according to a Spanish study published in October } \\
\qquad 2014 \text { in the journal of Annals of Psychology. }\end{array}$ \\
\hline 6 & $\begin{array}{l}\text { Create word } \\
\text { pictures }\end{array}$ & $\begin{array}{l}\text { Visualize the spelling of a word in your head, then try to think of other words that begin (or end) } \\
\text { with the same two letters. }\end{array}$ \\
\hline 7 & $\begin{array}{l}\text { Draw a map from } \\
\text { memory }\end{array}$ & $\begin{array}{l}\text { After returning home from visiting a new place, try to draw a map of the area. Repeat this exer- } \\
\text { cise each time you visit a new place. }\end{array}$ \\
\hline 8 & $\begin{array}{l}\text { Challenge your } \\
\text { taste buds }\end{array}$ & When eating, try to identify individual ingredients in your meal, including subtle herbs and spices. \\
\hline 9 & $\begin{array}{l}\text { Refine your hand- } \\
\text { eye coordination }\end{array}$ & $\begin{array}{l}\text { Take up a new hobby that involves fine motor skills, such as knitting, drawing, painting, or as- } \\
\text { sembling a puzzle. }\end{array}$ \\
\hline 10 & Learn a new sport & $\begin{array}{l}\text { Start practicing an athletic exercise that requires mind and body involvement, such as yoga, } \\
\text { futsal, or tennis. }\end{array}$ \\
\hline
\end{tabular}

perimental group performed sixteen 45 -minute active memory program sessions for 8 weeks, twice a week. The control group continued their usual routine activities. The posttest was implemented one day after the last exercise and training active memory skills sessions in the study groups. The obtained pretest-posttest results were analyzed in SPSS by Multivariate Analysis of Variance (MANOVA).

The overall exercise program was implemented for active memory training regarding the target children group's abilities as well as the attention and memory limitations of the experimental group subjects. Dehn's training program (2008) was employed to train active memory (Dehn, 2008) (Table 1). This program was designed and implemented in 10 training sessions for 3 months. Each training session was held for 45 minutes and twice a week in the learning disorders center of Babol City. During the exercises, students' joy and interest in the movement were reinforced by incentives, like prizes. Due to providing desired and humane response to the control group's cooperation, the researchers committed to training the controls in the second run of the training course after the completion of the first training course (i.e., related to the experimental group).

\section{Results}

To demonstrate the differences, first, the Mean \pm SD scores of experimental and control groups, then, MANOVA data are presented. The Mean \pm SD values of verbal understanding, perceptual reasoning, active memory, processing speed, and the overall scale of the study groups are displayed in Table 1.

Table 2 presents the variables' mean posttest scores increases in the experimental group (verbal understanding: 98.3; perceptual reasoning: 100,3; active memory: 89.2 ; processing speed: 99.9; overall scale: 98.3). Accordingly, the experimental group's mean scores increased after the intervention in these aspects.

Table 3 presents the Box's $M$ test data on the equality of variance error and degree of freedom. The significance level indicates that the assumed data did not question the equality of variance error. Table 4 provides the information related to the validity index of MANOVA.

Table 4 presents that the Wilks' Lambda value was equal to 0.0 , i.e., significant at $\mathrm{P} \leq 0.05$. The smallness of Wilks' Lambda value indicates a significant difference between the research groups. Table 5 represents MANOVA results; the inter-group effects concerning verbal un- 
Table 2. Mean $\pm S D$ of verbal understanding, perceptual reasoning, active memory, processing speed, and overall scale in the experimental and control groups

\begin{tabular}{|ccc}
\hline & & Mean \pm SD \\
Characteristic & Experimental & Control \\
\cline { 2 - 3 } & $85.2 \pm 15.317$ & $84.9 \pm 9.848$ \\
\hline Verbal understanding pretest & $98.3 \pm 12.970$ & $84.8 \pm 11.094$ \\
\hline Verbal understanding posttest & $91.9 \pm 17.317$ & $81.7 \pm 8.680$ \\
\hline Perceptual reasoning pretest & $100.3 \pm 15.048$ & $83.7 \pm 11.547$ \\
\hline Perceptual reasoning posttest & $82.2 \pm 4.662$ & $79.3 \pm 6.482$ \\
\hline Active memory pretest & $89.2 \pm 4.467$ & $78.8 \pm 8.69$ \\
\hline Active memory posttest & $91.8 \pm 16.396$ & $94.5 \pm 13.427$ \\
\hline Processing speed pretest & $99.9 \pm 12.458$ & $92.8 \pm 15.866$ \\
\hline Processing speed posttest & $84.5 \pm 14.238$ & $79.3 \pm 6.701$ \\
\hline Overall scale pretest & $98.3 \pm 12.184$ & $80.2 \pm 11.124$ \\
\hline Overall scale posttest & & PLANIICAL In PSYCH \\
\hline
\end{tabular}

derstanding, perceptual reasoning, active memory, processing speed, and overall scale.

Table 5 demonstrates that considering the pretest scores as the covariance (auxiliary) values of educational interventions on the verbal comprehension, perceptual reasoning, active memory, and overall scale has led to a significant difference between the experimental and control groups $(\mathrm{P}=0.280)$; however, at the processing speed scale, there was no significant difference between the study groups $(\mathrm{P}=0.280)$. The relevant results suggested that educational interventions were most influential on active memory and overall scale. The statistical power of approximately 100 reflects the sufficiency of the sample size.

\section{Discussion}

The necessity of paying special attention to children with SLD and creating minimum improvement in their cognitive and motor skills have led to extensive and progressive global research regarding the effect of training active memory on these children's intelligence profile; these are the most attractive skills in improving SLD in individuals. This study aimed at investigating the effects of active memory exercise on intelligence profile in children with SLD. The present study findings suggested that active memory exercise affected intelligence profile in verbal understanding, perceptual reasoning, active memory, and overall scale; however, some studies reported that the active memory capacity can increase with the training of the memory (Fuchs, Fuchs, Seethaler \& Barnes,

Table 3. Box's M-test results based on the assumption of variance equality between the study groups

\begin{tabular}{|c|c|c|c|c|}
\hline Scale & $\mathbf{F}$ & $\mathrm{df}_{1}$ & $\mathrm{df}_{2}$ & $\mathbf{P}$ \\
\hline Verbal understanding & 0.423 & 1 & 18 & 0.475 \\
\hline Perceptual reasoning & 0.635 & 1 & 18 & 0.365 \\
\hline Active memory & 0.854 & 1 & 18 & 0.385 \\
\hline Processing speed & 0.473 & 1 & 18 & 0.327 \\
\hline Overall scale & 0.568 & 1 & 18 & 0.394 \\
\hline
\end{tabular}


Table 4. Information related to the validity index of MANOVA

\begin{tabular}{|c|c|c|c|c|c|c|c|}
\hline Effect & Value & $\mathbf{F}$ & df & df Error & $\mathbf{P}$ & Eta & Test Power \\
\hline Pillai's Trace & 1.000 & 11958.037 & 5.000 & 14.000 & 0.0001 & 1.000 & 1.000 \\
\hline Wilks' Lambda & 0.0001 & 11958.037 & 5.000 & 14.000 & 0.0001 & 1.000 & 1.000 \\
\hline Hotelling's Trace & 4270.727 & 11958.037 & 5.000 & 14.000 & 0.0001 & 1.000 & 1.000 \\
\hline Largest Root Error & 4270.727 & 11958.037 & 5.000 & 14.000 & 0.0001 & 1.000 & 1.000 \\
\hline
\end{tabular}

2020). Additionally, educational interventions influenced verbal understanding, perceptual reasoning, active memory scales, and overall scale among children with SLD; however, it had no significant effect on their processing speed (Valencia-Naranjo \& Robles-Bello, 2017).

Studies precisely examining the present study subject are scarce; however, the obtained data were consistent with those of some relevant research studies (Köteles et al., 2020; Stedal et al., 2019; Homayounnia Firoozjah, Sheikh, Hemayattalab \& Shahrbanian, 2019; Gorman, Barnes, Swank \& Ewing-Cobbs, 2017; Valencia-Naranjo \& Robles-Bello, 2017). The collected results were in line with those of Sharington's theory of consolidation, which considers the neural process of consolidation. According to the consolidation theory, the repeated activation of the neural circuits and increased synaptic communication helps to establish learning; thus, it transforms information into long-term memory.

When information enters the long-term memory, the odds of data loss are very low. Repetition and mental rehearsal play an essential role in consolidating and transferring data to the long-term memory; the same occurs in transferring information from the short-term to the longterm memory (Sedigh \& Niusha, 2017). Active memory

Table 5. MANOVA data on the intergroup scale

\begin{tabular}{|c|c|c|c|c|c|c|c|}
\hline & Variables & $\mathbf{F}$ & df & MS & $\mathbf{P}$ & Eta & Test Power \\
\hline \multirow{5}{*}{ Model } & Verbal comprehension & 6.256 & 1 & 911.25 & 0.022 & 0.258 & 66 \\
\hline & Perceptual reasoning & 7.659 & 1 & 1377.80 & 0.013 & 0.298 & 75 \\
\hline & Active memory & 11.330 & 1 & 540.80 & 0.003 & 0.386 & 89 \\
\hline & processing speed & 1.239 & 1 & 252.05 & 0.280 & 0.064 & 19 \\
\hline & overall scale & 12.036 & 1 & 1638.05 & 0.003 & 0.401 & 91 \\
\hline \multirow{5}{*}{ Intercept } & Verbal comprehension & 1150.896 & 1 & 167628.05 & 0.0001 & 0.985 & 100 \\
\hline & Perceptual reasoning & 940.967 & 1 & 169280.00 & 0.0001 & 0.981 & 100 \\
\hline & Active memory & 2956.425 & 1 & 141120.00 & 0.0001 & 0.994 & 100 \\
\hline & Processing speed & 912.490 & 1 & 185666.45 & 0.0001 & 0.981 & 100 \\
\hline & Overall scale & 1170.593 & 1 & 159311.25 & 0.0001 & 0.985 & 100 \\
\hline \multirow{5}{*}{ Group } & Verbal comprehension & 6.256 & 1 & 911.25 & 0.022 & 0.26 & 66 \\
\hline & Perceptual reasoning & 7.659 & 1 & 1377.80 & 0.013 & 0.30 & 75 \\
\hline & Active memory & 11.330 & 1 & 540.80 & 0.003 & 0.40 & 89 \\
\hline & Processing speed & 1.239 & 1 & 252.05 & 0.280 & 0.06 & 19 \\
\hline & Overall scale & 12.036 & 1 & 1638.05 & 0.003 & 0.40 & 91 \\
\hline
\end{tabular}


practices promote the consolidation process by challenging one's mind to analyze information. Various studies revealed that children with SLD have poor performance in active memory (Bower et al., 2020). Considering the results of this study and similar investigations, active memory training can alleviate problems in children with SLD. The deficiency in the memory performance varies in different individuals; however, in children with SLD, working memory performance defects vehemently intensify learning problems. However, regardless of the presence or absence of other learning disorders, a stepby-step memory training method can be employed to help children with poor memory performance (Falck, Davis, Best, Crockett \& Liu-Ambrose, 2019).

Active memory is a part of the overall memory system. After the entrance of new information, while processing in mind, active memory assists us to store and record its (incorporate) important pieces. Children normally use this ability to do math or listen to a story. Active memory is a short-term use of memory performance. It is a set of skills that helps us to remember the required information to solve a problem or complete a task and be recall them as appropriate. Active memory is a fundamental part and foundation of all executive performance of the brain; a set of deep mental skills which makes facilitates planning and organizing issues and accomplishing motor skills (Hammill \& Allen, 2020).

Furthermore, some experts believe that active memory training provides proper opportunities to absorb various sensory input activities from the environment (Manni, Gitlin, Garzetta, Collier \& Fabbo, 2020). Purposeful behaviors affect the improvement of the interactional performance of the brain cortex and cerebellum; consequently, this process leads to improved cognitive skills, like attention. The tactile and motor stimulation obtained through group games causes the reinforcement of body image and the integration of the sensory perception from other modules. Cognitive activities are enjoyable, engage children's whole body, help them maintain concentration, and control behaviors induced by instant stimulus stimulation. This creative method emphasizes the uniqueness of each child in the treatment process as a value. Besides, it helps them to have an appropriate understanding of their surrounding environment (Kabadayi et al., 2020).

The strengths of this research can be expressed in the new idea along with the research as well as field and library research required to conduct this study, and the full support of parents and city school officials in this research work. The limitations of this research were the careful monitoring of the condition of individuals associated with interventions, as well as the age limit of individuals, and the small sample size. Employing direct cortical event detection technologies, such as electroencephalography and event-related potentials, as well as Functional Magnetic Resonance Imaging (fMRI) could reveal the underlying behavioral changes. Based on the obtained findings and some other relevant research, a strategy to improve and modify memory problems in children with SLD, i.e., implementing an age-appropriate active memory training program is suggested. At the beginning of each school year, memory and cognitive ability assessment and identification program for children with SLD should also be conducted to identify and treat them at the early stages. In addition to treatment centers, teachers' and parents' training/education could greatly help improve the condition of these children.

\section{Conclusion}

The present study results suggested that applying active memory exercise, as a non-pharmacological approach could help improve the intelligence profile of children with SLD. It is expected that this approach reduces the effects of SLD and prevent other bio-socio-emotional effects of children with SLD.

\section{Ethical Considerations}

\section{Compliance with ethical guidelines}

All ethical principles are considered in this article. The participants were informed of the purpose of the research and its implementation stages. They were also assured about the confidentiality of their information and were free to leave the study whenever they wished, and if desired, the research results would be available to them.

\section{Funding}

This research did not receive any grant from funding agencies in the public, commercial, or non-profit sectors.

\section{Authors' contributions}

All authors equally contributed to preparing this article.

\section{Conflict of interest}

The authors declared no conflicts of interest. 


\section{Acknowledgments}

The authors would like to thank all the participants and their families and the employees of the Center for the Development of Children with Learning Disorders who have sincerely collaborated with the researchers.

\section{References}

American Psychiatric Association. (2013). Diagnostic and statistical manual of mental disorders. $5^{\text {th }}$ Ed. Washington, DC: American Psychiatric Association. https://books.google.com/ books?id=-JivBAAAQBAJ\&dq

Bang, J. Y., \& Nadig, A. (2020). An investigation of word learning in the presence of gaze: Evidence from school-age children with typical development or Autism Spectrum Disorder. Cognitive Development, 54, 100847. [DOI:10.1016/j. cogdev.2020.100847]

Bower, C., Zimmermann, L., Verdine, B., Toub, T. S., Islam, S., \& Foster, L., et al. (2020). Piecing together the role of a spatial assembly intervention in preschoolers' spatial and mathematics learning: Influences of gesture, spatial language, and socioeconomic status. Developmental Psychology, 56(4), 686-98. [DOI:10.1037/dev0000899] [PMID]

Casado-Aranda, L. A., Sánchez-Fernández, J., \& Ibáñez-Zapata, J. Á. (2020). Evaluating communication effectiveness through eye tracking: Benefits, state of the art, and unresolved questions. International Journal of Business Communication, January. [DOI:10.1177/2329488419893746]

Dehn, M. J. (2008). Cognitive processing deficits. In R. J. Morris \& N. Mather (Eds.), Evidence-based interventions for students with learning and behavioral challenges (pp. 258-287). London: Routledge/Taylor \& Francis Group. https://psycnet.apa. org/record/2008-02912-012

Falck, R. S., Davis, J. C., Best, J. R., Crockett, R. A., \& Liu-Ambrose, T. (2019). Impact of exercise training on physical and cognitive function among older adults: A systematic review and meta-analysis. Neurobiology of Aging, 79, 119-30. [DOI:10.1016/j.neurobiolaging.2019.03.007] [PMID]

Fuchs, L., Fuchs, D., Seethaler, P. M., \& Barnes, M. A. (2020). Addressing the role of working memory in mathematical wordproblem solving when designing intervention for struggling learners. ZDM, 52(1), 87-96. [DOI:10.1007/s11858-019-010708]

Gabriely, R., Tarrasch, R., Velicki, M., \& Ovadia-Blechman, Z. (2020). The influence of mindfulness meditation on inattention and physiological markers of stress on students with learning disabilities and/or attention deficit hyperactivity disorder. Research in Developmental Disabilities, 100, 103630 [DOI:10.1016/j.ridd.2020.103630] [PMID]

Gorman, S., Barnes, M. A., Swank, P. R., \& Ewing-Cobbs, L. (2017). Recovery of working memory following pediatric traumatic brain injury: A longitudinal analysis. Developmental Neuropsychology, 42(3), 127-45. [DOI:10.1080/87565641.2017.1 315581] [PMID] [PMCID]
Groves, N. B., Kofler, M. J., Wells, E. L., Day, T. N., \& Chan, E. S. M. (2020). An examination of relations among working memory, ADHD symptoms, and emotion regulation. Journal of Abnormal Child Psychology, 48(4), 525-37. [DOI:10.1007/ s10802-019-00612-8] [PMID] [PMCID]

Hammill, D. D., \& Allen, E. A. (2020). A revised discrepancy method for identifying dyslexia. Journal of Pediatric Neuropsychology, 6, 27-43. [DOI:10.1007/s40817-020-00079-2]

Homayounnia Firoozjah, M., Sheikh, M., Hemayattalab, R., \& Shahrbanian, Sh. (2019). The influence of environment potentiality (affordances) on motor development in 6-9 years old children with intellectual disability. Sport Sciences for Health, 15(3), 497-502. [DOI:10.1007/s11332-019-00535-3]

Homayoun Nia Firoozjah, M., Namdar Tajari, S. (2019). [The effect of perceptual-motor exercises on the working memory of students with special learning disabilities with math problems (Persian)]. Motor Behavior, 10(34), 105-20. [DOI:10.22089/ MBJ.2019.6692.1738]

Kabadayi, S., Hu, K., Lee, Y., Hanks, L., Walsman, M., \& Dobrzykowski, D. (2020). Fostering older adult care experiences to maximize well-being outcomes: A conceptual framework. Journal of Service Management, 31(5), 953-77. [DOI:10.1108/ JOSM-11-2019-0346]

Kashani-Vahid, L., Kazemi Taskooh, S., \& Moradi, H. (2019) Effectiveness of "Maghzineh" cognitive video game on reading performance of students with learning disabilities in reading. Paper presented at 2019 International Serious Games Symposium (ISGS), Tehran, Iran, 26 December 2019. [DOI:10.1109/ ISGS49501.2019.9047004]

Knoop-van Campen, C. A. N., Segers, E., \& Verhoeven, L. (2020). Effects of audio support on multimedia learning processes and outcomes in students with dyslexia. Computers $\mathcal{E}$ Education, 150, 103858. [DOI:10.1016/j.compedu.2020.103858]

Köteles, F., Éliás, I., Szabolcs, Z., Körmendi, J., Ferentzi, E., \& Szemerszky, R. (2020). Accuracy of reproduction of physical training load is not associated with resting heartbeat perception in healthy individuals. Biological Psychology, 150, 107831. [DOI:10.1016/j.biopsycho.2019.107831] [PMID]

Maehler, C., \& Schuchardt, K. (2011). [Working memory in children with learning disabilities: Rethinking the criterion of discrepancy (Persian)]. International Journal of Disability, Development and Education, 58(1), 5-17. [DOI:10.1080/103491 2X.2011.547335]

Manni, B., Gitlin, L., Garzetta, G., Collier, L., \& Fabbo, A. (2020). Occupational therapy in nursing home. In C. Pozzi, A. Lanzoni, M. Graff, \& A. Morandi (Eds.), Occupational therapy for older people (pp. 101-124). Cham: Springer. [DOI:10.1007/9783-030-35731-3_6]

Margolis, A. E., Broitman, J., Davis, J. M., Alexander, L., Hamilton, A., \& Liao, Zh., et al. (2020). Estimated prevalence of nonverbal learning disability among North American children and adolescents. JAMA Network Open, 3(4), e202551. [DOI:10.1001/ jamanetworkopen.2020.2551] [PMID] [PMCID]

O'Keefe, M., \& Ward, H. (2020). Health profession curriculum and public engagement. In D. Nestel, G. Reedy, L. McKenna, \& S. Gough (Eds.), Clinical education for the health professions: Theory and practice (pp. 1-12). Singapore: Springer. [DOI:10.1007/978-981-13-6106-7_40-1] 
Palmqvist, L. (2020). Time to plan: How to support everyday planning in adolescents with intellectual disability [PhD. dissertation]. Linköping: Linköping University. [DOI:10.3384/ diss.diva-164916]

Sadeghi, A., Rabiee, M., \& Abedi, M. R. (2011). Validation and reliability of the Wechsler Intelligence Scale for Children-IV. Developmental Psychology: Journal of Iranian Psychologists, 7(28), 377-86. http://jip.azad.ac.ir/article_512280_en.html

Sedigh, H., \& Niusha, B. (2017). [The effect of Hatha yoga exercises training on executive functions (attention, concentration and working memory) of students with writing disorders (Persian)]. Middle Eastern Journal of Disability Studies, 7, 54. http://jdisabilstud.org/article-1-517-en.html

Shen, Ch., Luo, Q., Chamberlain, S. R., Morgan, S., RomeroGarcia, R., \& Du, J., et al. (2020). What is the link between attention-deficit/hyperactivity disorder and sleep disturbance? A multimodal examination of longitudinal relationships and brain structure using large-scale population-based cohorts. Biological Psychiatry, 88(6), 459-69. [DOI:10.1016/j. biopsych.2020.03.010] [PMID] [PMCID]

St Clair-Thompson, H. L., \& Gathercole, S. E. (2006). Executive functions and achievements in school: Shifting, updating, inhibition, and working memory. Quarterly Journal of Experimental Psychology, 59(4), 745-59. [DOI:10.1080/17470210500162854] [PMID]

Stedal, K., Ely, A. V., Kurniadi, N., Lopez, E., Kaye, W. H., \& Wierenga, C. E. (2019). A process approach to verbal memory assessment: Exploratory evidence of inefficient learning in women remitted from anorexia nervosa. Journal of Clinical and Experimental Neuropsychology, 41(6), 653-63. [DOI:10.1080/138 03395.2019.1610160] [PMID] [PMCID]

Sweller, J. (2020). Cognitive load theory and educational technology. Educational Technology Research and Development, 68(1), 1-16. [DOI:10.1007/s11423-019-09701-3]

Valencia-Naranjo, N., \& Robles-Bello, M. A. (2017). Learning potential and cognitive abilities in preschool boys with fragile $\mathrm{X}$ and Down syndrome. Research in Developmental Disabilities, 60, 153-61. [DOI:10.1016/j.ridd.2016.12.001] [PMID]

Wechsler, D. (2008). Wechsler memory scale. $4^{\text {th }}$ edition: (WMS-IV). San Antonio: Pearson. https://www.pearsonassessments.com/store/usassessments/en/Store/Professional-Assessments/Cognition-\%26-Neuro/Wechsler-Memory-Scale-\%7C-Fourth-Edition/p/100000281.html 
This Page Intentionally Left Blank 